\title{
Chemistry of Rubber*
}

\author{
Development in Our Knowledge of Caoutchouc from Columbus to Our Own Times \\ By S. C. Bradford, B.Sc.
}

IXDlarubBer, or caoutchouc, is essentially a hydrocarben, produced from a watery emulsion, or latex, obtained by tapping many tropical and sub-tropical the existence of rubber are said to have reachers of rope after the second voyage of Columbus to the New World in 1493-4, during which the natives were found to be in the habit of making playing-balls, bottles, waterproof boots and various other articles of a curious elastic gum. The earliest known reference to the substance occurs in a description by P. Martyr d'Anghiera in 1525 , of some playing-lalls seen by him in ball as of a solid matter, but "extremely porous and light. It soars higher than our balls, falls on the ground, and rebounds much higher than the level of ground, and rebounds much higher than the level of
the hand which it quitted it falls back again, and rebounds once more, although not to such a height this time, and the height of the bounce gradually diminishes." The Indians in Ecuador and Peru called the material "cahuchu" or "caucho," from which names ples were brought to Europe by travellers to adorn the curiosity cabinets of collectors. It was worth a guinea an ounce.

In 1731 two expeditions were organized by the Académie des Sciences to determine the figure of the earth. One of these, under the naturalist La Condamine, and Bouguer, an astronomer and mathematician, sailed to the tropical regions of South America. La Condamine occupied his leisure in studying the flora and fauna of Peru and Brazil. And in $\mathbf{1 7 3 6}$ he sent a small piece of rubber to the French Academy with a covering note in which he said: "There grows, in the covering note in which he said: "There grows, in the forests of the province of Esmeraldas, a tree called by the natives of the country 'Heve';' there flow's from it,
by simple incision, a liquor, white as milk, which gradually hardens and blackens in the air. The inhabitants make flambeaux of it . . . and boots which do not draw water, which, after having been blackened by holding them in the smoke, have all the appearance of real leather. They coat earthen molds in the shape of a hottle with it, and, when the resin is hardened, they lireak the mold and force out the pieces through the reck and mouth; they thus get a non-fragile bottle, rapable of centaining all kinds of liquid." La Condanine was unable further to pursue his investigations, but, at his suggestion, Fresneau, an engineer, stationed at Cayenne, made an exhaustive inquiry into the source and preparation of rubber, the account of $/$ which was communicated by La Condamine to the Académie des Sciences in 1751 .

The first chemical study of caoutchouc was published by Hérissart and Macquer in 1763, who examined the behavior of the material towards various solvents. But the substance appears to have remained a mere curiosity in Europe, until in 1770 Priestley, the discoverer of oxygen, suggested its use, under the name of India rubber, for erasing lead pencil marks. And this was, for many years, the main purpose to which it was, for many years, the main purpose to which it was devoted, although Grossart showed how to make
small tubes by cutting the bottles into strips, which small tubes by cutting the bottles into strips, which
were softened in ether, or essential oil, rolled on a were softened in ether, or essential oil, rolled on a
mandrel and allowed to dry, when the surfaces amalgamated. In 1785 M. Charles, who made the first ascent in a balloon filled with hydrogen, coated his aerostat with rubber dissolved in turpentine. Suggestions for making clothing waterproof were made by Peal and Besson in 1791, Johnson in 1797, Champion in 1811, and Clark in 1815. None of these met with much success. In 1820 Nadier discovered a method of cutting indiarubber into thread for making elastic fabrics. And in the same year Hancock founded in England the first rubber factory. But it was not until about 1825 that Mackintosh discovere the solubility of rubber in naphtha and successfully applied the solution to the fabrication of waterproof garments, from which time the modern rubber industry may be said to commence. In 1836, in consequence of the researches of Hancock, it was found that rubber could be welded into masses by energetic kneading under the action of moderate heat. The process was termed mastication and solved the problem of the manufacture of articles of daily use.

The material was quickly applied to the preparation of goloshes, bottles and many other objects. And, in

the United States particularly, vast sums of money * Reprinted from Science Progress (London). were invested in mills and plant for the manufacture of rubber goods. The discovery that these article were subject to the influences of the seasons cause widespread consternation, so many had an interest in the success of the gigantic speculation. Experience showed that in hot weather the substance melted and became adhesive, while in the cold it became obstinately brittle. A panic ensued, thousands of tons of rubber ly brittle. A panic ensued, thousands of tons of rubber
were thrown upon the market, and the immense capital became literally valueless.

It was now that Gondyear of New Haven, Conn determined, at all hazards, to save something from the wreck. Inspired with the belief that Nature would scarcely have disclosed so many of the merits of india rubber unless it possessed aclditional qualities of value to mankind, and oblivious of opposition and scorn, he to mated himself to the prosecution of the research. devoted himself to the prosecution of the research.
After suffering much hardship and even imprisonment for debt, he was rewarded in 1839 by the discover of the process of vulcanization, which overcame the influence of seasonal changes and adapted the materia to countless purposes of mankind. The result was at tained by heating the gum with an admixture of sulphur to a temperature of $270^{\circ} \mathrm{F}$. In 1844 Hancock observed that the same result was obtained by dipping patented a method for molding objects in caoutchouc, patented a method for molding objects in caoutchouc,
which was the starting-point of molds for solid and hollow articles. The greatest impetus it ever receive was undoubtedly given to the industry by the reinvention, in 1888, of the pneumatic tire. An air-filled tire for use with carriages had been patented by Thomson in 1845 , but, partly owing to faulty construction and partly because its advantages at low speeds were not sufficient to counter-balance the high cost of the large tires employed, the invention had been allowed to drop. The advent of the safety bicycle, with small wheels to which springs could not easily be attached, led Dunlop independently to discover and patent the idea.

Previous to the $u$ tilization of rubber in the chemical laboratory, apparatus was connected, if possible, by means of glass tubes bent twice at suitable angles. Oc casionally one piece of apparatus was ground to fit another. Otherwise, for such purposes as connecting retorts with receivers, lutes were used. Thomso says, in his System of Chemistry, sixth edition, 1820 "The lute most commonly used by chemists, when ve sels are exposed to heat, is fat lute, made by beating together in a mortar fine clay and boiled linseed oil

The accuracy of chemical experiments depend almost entirely, in many cases, upon securing the joinings properly with luting. The operation is always tedious; and some practice is always necessary before one can succeed in luting accurately." The lutes wer covere with strips of bladder or linen dipped in glue made fast with cord and allowed to dry before com mencing the experiment. It is not surprising that indiarubber was adopted almost as soon as it became availa ble. The use of caoutchouc connecting-pieces was fir described by Berzelius in 1814, in connection with his method of ultimate organic analysis. He says: "I take a thin piece of [unvulcanized] caoutchouc, an heat it a little. I bend it and cut off from the bending a small portion with a pair of scissors. The cut surfaces unite together, and form a tube. If they do not unite, let them be pressed with the nails against each other, taking care not to touch them with the fingers." In his Chemical Manipulation, 1827, Faraday remarks "Caoutchouc connecting pieces are easily made, an are of such constant use in attaching tubes and appa ratus for the conveyance of vapors and gases, that a number of them, from an inch to two inches long, an from a quarter to half an inch in diameter, should be kept ready.... They are most easily made of the sheet caoutchouc, prepared by Mr. Hancock, which is about the tenth of an inch thick, and may be had in pieces ten or twelve inches square. A piece of this caoutchouc about an inch and a half square, is to be slightly warmed until it becomes flexible and soft, and then put round a glass rod or other cylindrical body, rather smaller than the intended tube; the projectin edges are to be pinched together, and when they hav slightly adhered, cut through with a pair of sharp scissors; this will ... leave the two edges slightly by immediately bringing these edges into contact throughout the whole extent of the cut surface . . . by applying a thumb-nail. When firmly pressed togethe while warm, the adhesion is such that the tube will tear elsewhere as readily as at the junction. . They are frequently useful of a conical form." A other plastic material through an annular opening for the purpose of making continuous tubing was granted to Hunt in 1850 . Soon after rubber tubing appears to to Hunt in 1850 . Soon after rubber tubing appears to
have been adopted for chemical purposes, though this have been adopted for chemical purposes, though this
was probably made from cut sheet. The first reference to such use occurs in Aleel and Bloxam's Handbook of ('hl'mistry, 1854: "Small pieces of vulcanized Indian rubber tuling, which is now macle of almost any dimensions, answer the purpose of these connectors exceedingly well; they may not allhere to the glass quite by tying them firmly upon the tubes at each extrenby tying them firmly upon the tubes at each extren-
ity." But the old form was not easily superseded, and ity." But the old form was not easily superseded, and
in 1857 we find in Greville William's Handbook of in 1857 we find in Greville William's Handbook of
Chc'mical Itanipulations "Vulcanized India-rubber tubes . . . are in almost every case preferable to those made in the laboratory from sheet caoutchouc; but those which are used to connect the chloride of calcium much better of the latter kind. The reason is that the vulcanized ones are less adhesive."

In 1844 Hancock patented a process for molding stoppers of gutta-percha, or gutta-percha and caoutchouc. But rubber stoppers for chemical purposes do not seem to have come into use until about 1865 . The introduction may be attribute to Sir William Perkin Mr. Tutin relates, on personal authority, that, impressed with the unsuitability of ordinary corks for organic analysis, Sir William was walking one day in London, when he happened to see a block of rubber in a shop window. The idea occurred to him of cutting stoppers of rubber, and was put into execution forthwith. A reference to their use appears in 1872 in the Chemical News, where Donkin advocates dipping the knife or cork-borer in solution of caustic potash whel desiring to cut or bore indiarulber corks.

Natural rubber is obtaine from the latex by a process of coalization apparently depending on the coagulation of the protein, or other protective colloid. The coagulation is brought about by heat, by the addition of acids, generally acetic, and by other methods. The globules of rubber rise through the liquid, coalesce and yield a tough elastic mass, which may be regarded a an emulsoid gel. Raw rubber contains as its principal constituent a hydrocarbon of the composition $\mathrm{C}_{10} \mathrm{H}_{18}$, the amount of which may reach as much as 95 per cent. Much early work was done on the destructive distillation of rubber from the time of Dalton. Its empirical constitution was determined from analyses made by Faraday, Berzelius, Ure and others. The first important chemical research on this subject was made by Greville IVilliams in 1860. He distilled rubber in an iron vessel at a low temperature, and obtained isoprene, $\mathrm{C}_{5} \mathrm{H}_{8}$, and cautchine, $\mathrm{C}_{10} \mathrm{H}_{18}$, which latter substance Wallach subsequently showed to be identical with formation of isoprene into a rubber-like body, of which formation of isoprene into a rubber-like body, of which evidently considered caoutchouc to be a polymer of isoprene. In 1875 Bouchardat investigated the products of the distillation of rubber, and came to the conclusion that the substances he obtained, $\mathrm{C}_{10} \mathrm{H}_{1}$ $\mathrm{C}_{15} \mathrm{H}_{24}$, etc., including rubber itself, are polymers of isoprene. In 1879, while preparing the hydrochloride of isoprene, by shaking with concentrated hydrochloric acid, a rise of temperature indicated that combination had occurred, but on distillation a solid residue remained which was found to have "the elasticity and other properties of rubber itself."

In 1882 Tilden showed that the colorless syrupy substance resulting from the atmospheric oxidation of isoprene is converted into true rubber when brought into contact with strong aqueous hydrochloric acid, or nitrosyl chloride, remarking that "It is this character of isoprene which gives it a somewhat practical in terest, for, if it were possible to obtain this hydrocarbon from some other and more accessible source, the synthetic production of rubber could be accomplished." At the same time Tilden proposed the constitutiona formula for isoprene, $\mathbf{C H}_{2}: \mathbf{C}\left(\mathrm{CH}_{3}\right) . \mathrm{CH}: \mathbf{C H}_{2}$. Two years later he showe that isoprene can be obtained by the destructive distillation of turpentine, indicating the first possible process for the commercial prepara the first possible process for the commercial prepara-
tion of rubber. He noted that polymerisation took 
place most readily after a preliminary heating which vielded an oily body, and suggested that the analogues of isoprene, $\mathrm{C}_{4} \mathrm{H}_{8}, \mathrm{C}_{8} \mathrm{H}_{10}$, etc., might be made to polymerise to a series of rubber hydrocarbons. In 1887 Wallach showe that isoprene change to a rubberlike body under the action of light alone, thereby anticipating Tilden's independent discovery five year later. In a paper published in 1892 Tilden remarks "I was surprised... at finding the bottles containing isoprene from turpentine entirely changed in appearance. In place of a limpid, colorless liquid, the bottle contained a dense syrupp in which were floating several large masses of solid, of a yellowish color. Upon examination this turned out to be indiarubber. ... The artificial rubber unites with sulphur in the same way as ordinary rubber, forming a tough elastic compound Tilden was thus the first to show that synthetic rubber can be vulcanized like natural caoutchouc. Tilden's can be vulcanized like natural caoutchouc. Tilden's and Bouchardat's work was confirmed by Weber in 1894,
so that the scepticism expressed by Klages and Harries as to the methods emplnyed, and the identity of the product obtained, is remarkable.

The constitution of rubber has been considerably elucidated by the extensive researches of Harries, dat ing from 1901 and onwards. He had found that when unsaturated substances were treated with ozone, molecule of ozone added itself at each double bond yielding an ozonide, which, on treatment with steam, split up into two fractions at the point of addition. In this way he determined the constitution of oleic acid. From rubber he obtained a body of the molecular weight indicated by the formula $\mathrm{C}_{10} \mathrm{H}_{18} \mathrm{O}_{6}$. This was decomposed by steam into lævulinic aldehyde, $\mathrm{CH}_{\text {, }}$ $\mathrm{CO} . \mathrm{CH}_{2} \cdot \mathrm{CH}_{2}, \mathrm{CHO}$, lævulinic acid, $\mathbf{C H}_{3} \cdot \mathrm{CO} \cdot \mathrm{CH}_{2}$ $\mathrm{CH}_{2}$. $\mathrm{COOH}$, and læuvulinic aldehyde superoxide, $\mathbf{C H}_{3}$. $\mathrm{CO} . \mathrm{CH}_{2} \cdot \mathrm{CH}_{2}$. CHO. Harries explained the action

by the following struetural formulæ:
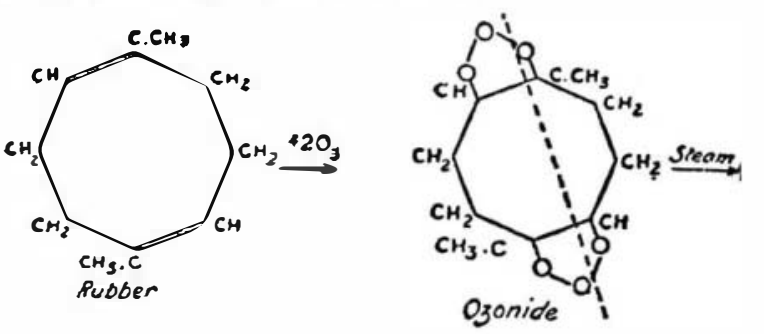

$\left.\right|_{C H_{3}} ^{C C=0}=0$

aevulinic Aldehyde

Superoxide

This indicates that the rubber nucleus is an eightmembered ring. And its formation from isoprene is represented thus :

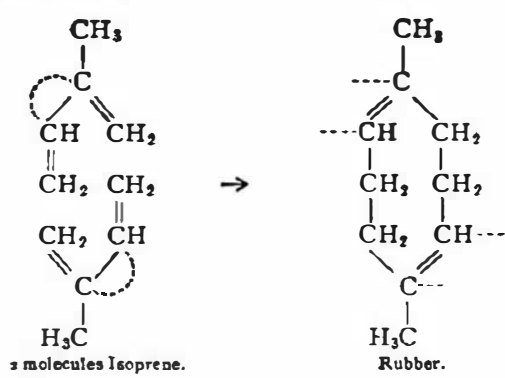

The dotted lines denote partial valencies according to Thiele's theory. And Harries supposed that an indefinite number of rings might be linked together at the double bonds. This view was criticised by Pickles in 1910 , who preferred to think that the $\mathrm{C}_{5} \mathrm{H}_{8}$ nuclei unite to form long chains as :

$\mathrm{CH}_{3}$<smiles>CC</smiles>

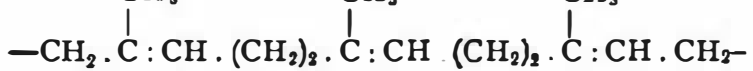
In 1914 Harries proposed a new formula for rubber consisting of five $\mathrm{C}_{5} \mathrm{H}_{8}$ groups united to form a $\mathrm{C}_{20}$ ring. Rubber forms a number of addition compounds with the halogens, sulphur, etc. The simplest and most definite of these is the tetrabromide, $\mathrm{C}_{10} \mathrm{H}_{18} \mathrm{Br}_{4}$, in which two atoms of bromine have attached themselves at each double bond. The sulphur derivatives are obtained in the process of vulcanization. Weber concluded that there is a series of sulphur compounds between the limits $\left(\mathrm{C}_{10} \mathrm{H}_{16}\right)_{10} \mathrm{~S}_{2}$ and $\mathrm{C}_{10} \mathrm{H}_{18} \mathrm{~S}_{2}$, the latter corresponding to ebonite, though later work has thrown considerable doubt on the accuracy of his deductions.

The determination of the molecular weight of caoutchouc has not so far been accomplished. In the liquids usually employe to dissolve it, rubber is present in the colloidal state, and each particle probably consists of a large aggregate of molecules. So that osmotic pressure, freezing point and boiling point methods are inapplicable. As, however, in 1912 Walden discovere that starch formed a true solution in formamide, with the aid of which he found the molecular weight to correspond to the comparatively simple formula $\left(\mathrm{C}_{6} \mathrm{H}_{10} \mathrm{O}_{5}\right)_{4}$, a true solution of rubber may eventually be obtained. In the meantime, as its simpler soluble derivatives have only ten carbon atoms in the molecule, it may be assumed that rubber contains no more than this number. That the molecules of caoutchouc an those of many of its derivatives are associated with each other to a high degree is in accordance with their colloidal condition.

From 1907 onwards the attention of a number of chemists began to be directed to the problem of the artificial production of rubber. Activity in this countr was centered in the Synthetic Products Company, while in Germany the question was taken up by the Baye Company and the Bädische Anilin und Soda Fabrik Previous observations had shown that the homologue of isoprene polymerise to substances related to caoutchouc possessing properties varying from sticky resi to brittle solids. So far as the consumer is concerned, the exact constitution of a body is unimportant, provided its physical properties are suitable. So that the product require is not necessarily true rubber but a substance having similar physical properties. The more important members of the isoprene series The more important members of the isoprene series
that have been considered are : erythrene, or buta-1 $: 3$ diene, $\mathrm{CH}_{2}: \mathrm{CH}$. $\mathrm{CH}: \mathrm{CH}_{2}$; piperylene, or 1-methylbuta-1 : 3-diene, $\mathrm{CH}\left(\mathrm{CH}_{3}\right): \mathbf{C H} . \mathrm{CH}: \mathrm{CH}_{2}$; and iso prene, or 2-methyl-buta-1 : 3-diene. Many methods for the preparation of these bodies have been suggested Turpentine was originally proposed as the raw maTurpentine was originally proposed as the raw ma-
terial, but, owing to its limited supply and frequent fluctuations in price, attention was directed to othe substances, such as wood, starch, sugar, acetylene, coaltar and petroleum. In 1910 the Synthetic Product Company patented a method of preparing isopren from fusel oil. The fraction distilling at $128^{\circ}-131^{\circ}$ consists of iso-amyl alcohol, $\left(\mathrm{CH}_{3}\right)_{2}: \mathbf{C H} \cdot \mathbf{C H}_{2}$ $\mathrm{CH}_{2} \mathrm{OH}$, and active amyl alcohol, $\mathrm{CH}_{3} \cdot \mathrm{CH}_{2} . \mathrm{CH}\left(\mathrm{CH}_{3}\right)$ $\mathrm{CH}_{2} \mathrm{OH}$, which are converted into their monochlorides with hydrochloric acid, and then chlorinated in such a way that only dichlorides result, such a $\left(\mathrm{CH}_{3}\right)_{2} \mathrm{CH} \mathrm{CHCJ} . \mathrm{CH}_{2} \mathrm{Cl},\left(\mathrm{CH}_{3}\right)_{2} \mathrm{CCl} . \mathrm{CH}_{2}, \mathrm{CH}_{2} \mathrm{Cl}$ and $\begin{aligned} & \mathrm{CH}_{2} \mathrm{Cl} \\ & \mathrm{CH}_{3}\end{aligned}>\mathrm{CH}, \mathrm{CH}_{2} . \mathrm{CH}_{2} \mathrm{Cl}$. These are passed over soda-lime at $470^{\circ}$, giving a 40 per cent. yield of isoprene. As the amount of fusel oil available is small, Fernbach and Stange endeavored to devise a means for its production in larger quantities. And in 1911 they patented a method involving the cheap production of butyl alcohol and acetone by the fermentation of starch with the aid of the butylic bacillus. Butyl Chloride obtained from the alcohol is then care fully chlorinated with the production of the dichlorides $\mathrm{CH}_{3} . \mathrm{CH}_{2}$. $\mathrm{CHCl} . \mathrm{CH}_{2} \mathrm{Cl}, \mathrm{CH}_{3} . \mathrm{CHCl} . \mathrm{CH}_{2} . \mathrm{CH}_{2} \mathrm{Cl}$ an $\mathrm{CH}_{2} \mathrm{Cl} . \mathrm{CH}_{2} . \mathrm{CH}_{2} . \mathrm{CH}_{2} \mathrm{Cl}$ which yield butadiene on passin over heated soda lime.

Various means have been proposed for the polymerization of the hydrocarbons obtained. In 1909 the Bayer Company employed the application of heat to the substance contained in sealed tubes. The following yea Harries found that the presence of acetic acid accelerate the change. The Bayer Company showed that the acetic acid probably acted as a diluent. And the use of other agents such as alkalies, alkaline earths, urea, blood, etc., with or without preliminary heating, have been suggested.

The most dramatic incident in the race between the English and German firms was the almost simultaneou discovery of the value of sodium as a polymerizin agent. Harries found, at the end of 1910 , that sodium causes the change to take place quickly, and practically quantitatively, at a low temperature. The method was patented ly the Bayer Company early in 1911. Dr. Matthiws had, however, been investigating the action of sodium on dimethyl-allene, and in July, 1910 , it occurred to him to seal up some isoprene with sodium. Reluctantly returning to town during a holday in August, he discovered that the tube containe a portion of remarkably good rubber. By Septembe the contents had set to a solid amber-colored mass Further work indicated the importance of sodium as a general polymerizing agent for these hydrocarbon and a patent was applied for on October 25, three months before the German application.

While possessing the same physical properties synthetic rubbers produced by other methods, the rubbers obtained by the action of sodium appear to have a somewhat different chemical constitution. Ozonides are formed less readily, and give rise to other products than lævulinic acid and aldehyde. The constitution of sodium isourene caoutchouc is believed to be dimethylcycloöctadiene with conjugated ethylenic linkages.

\section{A New Theory of Jupiter's Satellites}

Prof. W. de Sitter has published in the Annals of the Leiden Observatory, 1918, xil, part 1, the outline of an important new mathematical theory of Jupiter's satellites. A much abridged summary is also given in K. Akad. Amsterdam, Proc., 1289, 1918, xx. The principal difficulty in the theory of the four old satellites of Jupiter arises from the fact that the mean motions of Jupiter arises from the fact that the mean motions
of the three inner satellites are commensurable. The mean motion of the fourth satellite is not commensurable with those of the others, and its theory does not present any particular difficulties, in so far as the periodic inequalities are concerned; it is similar to but simple than the lunar theory, for the ratio of the month and year is only about $1 / 260$. The secular perturbations of the center are, however, intimately connected for the four satellites, so that it is impossible to separate them, and the apparently simple and obvious course of having one theory for the three inner satellites and another theory for the fourth cannot be adopted.

In the old theory of the motion of the satellites, the undisturbed Keplerian eclipses are taken as intermediary orbits for the four satellites, and from these orbits by the addition of perturbations and variations, the complete solution is derived. This method of procedure is the best in the case of the fourth satellite but not for the inner three. The new theory of de Sitter is chosen so as to be the best for the case of the inner satellites, and this more than compensates for the somewhat increased difficulties in the case of the fourth satellite.

The motion of the satellites can be described as a uniform motion in a circle with superposed inequalities. The inequalities in longitude and radius-vector can be classfied according to period into four separate groups (1) Short-period inequalities with periods not exceeding seventeen days, and including the "equations of the center" and the "great inequalities:" (2) Inequalitie with periods between 400 and 5500 days: these inequalities are negligible in the radius-vector and are zero for the fourth satellite; (3) Librations of the inner satellites with a period of about seven years; (4) Long-period inequalities with periods longer than twelve years. The "great inequalities" and those of groups (2) and (3) arise through the commensurability of the mean motions and in the usual theory have small divisors.

In the new theory, intermediary orbits are used in which the expressions for the mean longitudes, mean anomalies, and lonbitudes of the perijoves of the satellites are riporously satisfied. The special features which make this solution a good first approximation in the case of the three inner satellites are the moving perijove and the fact that the induced equations of the tenter or "great ineaqualities" are larger than the free or ordinary equations. For the fourth satellite the or ordinary equations. For the fourth

In the new theory the equations of the center are treate in much the same way as in the usual theory but the great inequalities are not treated as perturbations, since they are of the first order. The intermediary orbit is not periodic, but contains only the principal terms of the periodic solution: to form the complete solution from this orbit are added perturbations arising from those parts of the perturbative function which were originally neglected and variations due to the fact that the actual constants of integration do not exactly fulfil the conditions of the intermediary orbit. With this method of treatment, the small divisors which arise in the old theory are avoided they enter the equations of condition of the intermediary orbit, but do not reappear after these have been solved The publications referred to above treat of the theory of the longitudes and radii-vectores; the theory
of the latitudes is to be treated in detail in the second part of the volume

In connection with the derivation of the potential function an interesting point is noted. Certain terms were neglected by Laplace which contain a small factor whose value is dependent on the form of Jupiter and the distribution of its mass, but which there was the no means of evaluating. Similar terms were neglected in the complementary part of the perturbative function. The neglect of these terms was justifiable in view of the limit of accuracy which Laplace had set himself Subsequent writers, however, have copied Laplace's perturbative function, neglecting the terms in question, although in the development of other terms quantities of the same or higher order of smallness have been included. The supposed degree of accuracy has therefore not been obtained. 